This is the authors' preprint. The published version of the paper is published in the European Journal for Person-Centred Healthcare, 2020; 8(3): 345-354.

http://www.ejpch.org/ejpch/article/view/1863

\title{
The ethical and epistemic roles of narrative in person-centred healthcare
}

\begin{abstract}
Mary Jean Walker, Wendy A. Rogers, and Vikki Entwistle
Positive claims about narrative approaches to healthcare suggest they could have many benefits, including supporting person-centred healthcare (PCH). Narrative approaches have also been criticised, however, on both theoretical and practical grounds. In this paper we draw on epistemological work on narrative and knowledge to develop a conception of narrative that responds to these concerns. We make a case for understanding narratives as accounts of events in which the way each event is described is influenced by the ways other events in the narrative are described. This view of narratives recognises that they can contribute knowledge of different kinds of connections between events: not just causal, and not just of patient's perspectives. Additionally, narratives can add further epistemic value by suggesting potentially useful lines of inquiry. We take narrative approaches to healthcare to include clinicians considering both patients' informational offerings and their own professional understandings as narratives. On this understanding, our account is able to overcome the major theoretical and practical criticisms that have been levelled against the use of narrative approaches in healthcare, and can help to explain why and how narrative approaches are consistent with $\mathrm{PCH}$.
\end{abstract}

Several authors have argued that that clinical attention to narratives - that is, listening to the narratives of patients in the clinical encounter and/or recognising narrative structures in medical knowledge - can improve patient care in a number of ways. Many of the claims made about the benefits of attending to narratives overlap with features of person-centred healthcare (PCH). As such, narrative approaches (as we will refer to them) can be considered potential means of supporting $\mathrm{PCH}$.

$\mathrm{PCH}$ has been formulated in a range of ways, but loosely, aims to counter problems in healthcare related to tendencies to reductive and dehumanising care of patients. These tendencies have been linked to the enduring influence of the biomedical model (perpetuated by features of medical education [1, p.90], institutional traditions [2], and 
increasing emphasis on technologies [3;4;5]); and constraints in clinical practice, such as financial, time, and institutional pressures, that (allegedly) limit clinicians' capacities to engage with patients as persons. ${ }^{1}$ These influences and pressures can lead to healthcare that is disease-centred, clinician/system-centred, or technology/measurement-centred, with negative impacts on patients $[6, \mathrm{p} .29]$. In contrast, $\mathrm{PCH}$ can be understood as involving: treating patients as persons worthy of respect and compassion; recognising and responding to patients' subjective experiences of illness and care, and concerns about their identities and life projects; and developing therapeutic relationships that support (or at least do not undermine) patients' abilities to participate actively in their own healthcare (including to ensure their personal values influence treatment decision-making) [6, pp.34-36]. ${ }^{2}$

Some discussions of PCH claim that clinical attention to narratives can facilitate the achievement of PHC, while narrative approaches share many motivations with PHC. Like PHC, narrative approaches seek to recognise patients as individuals and avoid the homogenisation of patients' experiences that can be associated with an overly biomedical emphasis [8]. Advocates of narrative approaches claim that they can: improve patientclinician communication, enabling clinicians to better understand patients' situations and perspectives, and so more effectively communicate information to patients; allow patients to be heard empathically and develop understanding of the meaning of their experiences; and develop clinicians' capacities for empathy and understanding. An additional claim is that recognising narrative structures inherent in medical knowledge can help counter tendencies to dehumanise patients and the biomedical assumptions thought to encourage those tendencies.

Narrative approaches face theoretical and practical issues, both of which relate in part to how the concept of narrative is understood. One critique of narrative approaches is that the concept of narrative is so broad that it renders claims about attending to narratives trivial: if

1 Throughout this paper we use 'clinician' to refer to any healthcare professional. For a detailed review of definitions of $\mathrm{PCH}$ see [6].

$2 \mathrm{PCH}$ can additionally be understood to require that clinicians are treated as persons [6;7]. Here we focus on how narrative can help clinicians work in person-centred ways with patients. 
every communication is narrative, the concept is emptied of specificity $[9 ; 10] .{ }^{3}$ Others argue that narrative is too narrow a concept to encompass the illness experience of all patients $[11 ; 12 ; 1]$. Practically, time constraints may prevent clinicians from listening to detailed narratives from every patient; not every patient may want depth of engagement in their narrative [13]; and sometimes there are reasons for clinicians to be wary of taking patients' statements at face value.

In this paper, we aim to clarify the potential contribution of clinical attention to narratives in achieving some of the aims of $\mathrm{PCH}$. Specifically, we investigate what knowledge narratives can contribute, and use insights from this investigation to develop a pluralist account of the epistemic (and related ethical) value that narrative approaches can add in health care contexts. Our account supplements existing theoretical work in narrative approaches which focuses primarily on the role of narrative in developing ethical goods like empathy and practical reasoning $[14 ; 15$, Ch.8].

In section 1, we review the claims of narrative approaches in relation to improving patient care. In section 2 we overview some critiques. In section 3 we develop our pluralist conception of narrative. In section 4, we show how this conception resolves the theoretical criticisms, and in section 5, identify the direction it provides in addressing practical issues.

\section{Narrative and the goals of PCH}

The concept of narrative is characterised diversely and sometimes quite broadly in descriptions of narrative approaches in healthcare. Montgomery Hunter states that by 'narrative' she means "a more or less coherent written, spoken, or (by extension) enacted account of occurrences, whether historical or fictional" [16, p.306]. Greenhalgh and Hurwitz [17, pp.3-4] point to four typical features of narratives: narratives include events occurring sequentially over time; involve a narrator and a listener; are concerned with individuals and their perspectives; and involve us emotionally. Charon examines five features of narratives: narratives represent temporal relations between events; focus on particular events and agents; connect events both causally and contingently; are intersubjective in the sense that

3 An even broader range of claims are in fact made for narrative than the one we identify here [9]. We focus on those related to clinical encounters. 
both clinicians' and patients' perspectives affect what narrative is told; and have ethical dimensions since they involve this intersubjective relationship [14, pp.40-56].

In this section we overview four main claims of narrative approaches that are relevant for PCH, namely that: (1) clinical attention to patient narratives is a good way to obtain information that facilitates better care $[17 ; 18]$; $(2)$ narratives can help both patients and clinicians understand illness experiences [8;19]; (3) use of narrative approaches helps clinicians to develop listening skills and empathy [14]; and (4) recognition by clinicians of narrative structures in medical knowledge will help them avoid problematic tendencies associated with the biomedical model $[14 ; 15]$.

The first claim, that in a particular clinical encounter, listening to a patient's narrative provides information to the clinician, is unpacked in several ways and supported by a range of examples. Narrative information reportedly aids accurate diagnosis, informs interpretation of physical and laboratory findings, focuses diagnostic work-ups, and assists in choosing therapeutic options acceptable to and understood by the patient [14, p.9]. While some diagnoses can be made on the basis of physical signs, in many cases it is necessary to listen to accounts of symptoms and their contexts in order to distinguish likely causes, for example of epigastric pain or dizzy episodes. Similarly, understanding what treatments will be acceptable to and workable for a patient may require knowledge of her commitments, daily activities, and available resources, and not only her physical condition. The claim is not just that a clinician needs information about their patient for these purposes, but that allowing patients to provide the information in a narrative form is an epistemically and ethically advantageous way to acquire it, in contrast to other methods such as clinician-directed questioning. Allowing patients to provide information in narrative form is an efficient way to collect information of relevance to the patient's condition, and contributes to relationship-building and other ethically-oriented goals as well as supporting better health outcomes.

Second, listening to patients' narratives can be itself a therapeutic act. It allows patients to be heard and to engage in practices of self-interpretation that can increase selfunderstanding $[18$, p.1898;14, p.66;17, p.7]. This can be particularly important for patients 
who are struggling to make sense of their illness experience, whose illness has disrupted their life or sense of identity [8;20]. Listening to patient's narratives is a way for clinicians to bear witness to patients' suffering, be empathic, and establish a therapeutic relationship, all of which are important elements of the clinician's ethical responsibilities [18, p.1899].

Third, over time attending to patients' narratives improves clinicians' listening skills, which increases their capacities to gain knowledge from patient narratives and to fulfil these ethical responsibilities. Charon argues that listening to patient narratives (especially when combined with other practices like narrative writing) develops empathy, respectfulness, altruism, imagination, and interpretation [14, p.8-10]. Montgomery Hunter argues that attention to patient narratives can improve clinicians' practical reasoning as it requires engagement with others' perspectives [16, pp.307-8; pp.312-3;15, Ch. 8].

Finally, the claim is made that clinical recognition of narrative structures in medical knowledge can help counter an overly biomedical perspective and the dehumanisation of patients thought to follow from it [10]. Kleinman's detailed accounts of patients' stories, for example, compellingly demonstrate that the meanings of illness are largely omitted by the biomedical perspective [19]. Montgomery Hunter and Charon provide theoretical arguments to underpin this point. Both distinguish, following Balint, between the patient's illness narrative, and the medical narrative which the clinician creates, reinterpreting the events in pathophysiological terms along with other events such as clinical examinations and tests $\left[14\right.$, p.22;15, Ch.1-2]. ${ }^{4}$

Clinicians are typically taught to regard medical understanding as objective and the patient's as subjective [1]. While there are senses in which this is true, it can enforce a view that the medical understanding is the 'correct' one while the patient's lacks validity. This can hamper communication, and seem to the patient a dismissal of their experience [15, p.13]. Regarding both clinicians' and patients' understandings as narratives implies that they are both interpretations, which represent different perspectives and have different purposes, but each can be valid. Clinicians interpret symptoms in the context of their medical

4 We leave aside further distinctions, such as between the medical narrative told to the patient and those told between colleagues or in educating medical students. 
knowledge and seek to fit them into a nosological pattern, while patients interpret symptoms within the context of other events in their lives [14, p.22]. Recognising this, it is claimed, can help shift clinicians' focus beyond an overly biomedical one and avoid the kinds of devaluing of patient perspectives that hinder empathic engagement and therapeutic alliance, or lead to dangerous neglect of relevant information patients provide $[15 ; 21 ; 22]$.

\section{Critiques of narrative approaches}

These claims about narrative approaches further demonstrate the diversity in conceptions and forms of narrative. Across the spectrum, they include everything from brief, spontaneous patient statements, to literary narratives that present a rich, imaginatively challenging account of subjective experience. Charon talks of the patient's narrative including not only their statements, but also clinical signs, lab results, and treatment responses, while other scholars include literary forms such as poetry in the category [15, p.305;17, p.13;11]. Sometimes 'narrative' seems to be used to refer to anything related to subjective experience or to the 'human aspects' of medicine $[9$, p.74;10]. If such a broad range of things count as narratives, it seems unclear whether 'listening to a patient's narrative' means anything more than 'listening to a patient', or what it adds to consider empathy, recognition of perspective, and so on, as related to listening to narratives.

At the same time, narrative approaches have been criticised on the ground that narrative is too narrow a concept to capture all possible illness experiences. This critique is often aimed at specific accounts that offer a narrow, more precise conception of either what counts as a narrative or of what counts as a beneficial narrative. We illustrate this using the work of Arthur Frank, who suggests that illness narratives tend to fall into three main categories chaos, restitution, and quest - and implies that quest narratives are the preferable kind [8]. Frank is primarily focused on understanding illness experience, in situations where severe or long-lasting illness disrupts a person's life or capacity to find meaning in their experiences, rather than the kind of minor matters that can also be found in everyday clinical consultations. Chaos narratives are 'anti-narratives' where narrative ordering is lost; restitution narratives have the form 'I was once healthy, now I am sick, but I can be healthy again'; while quest narratives see illness experiences as transformative. Discussing chaos narratives, Frank gives the example of Nancy, a woman living with chronic illness while 
dealing with multiple family problems including caring for her mother who has Alzheimer's. Her story involves a constant telling of the present moment with "no memorable past and no future worth anticipating", because she is so occupied by the horror and difficulty of the present moment that narrative order cannot be imposed [8, p.99]. Although Frank emphasises the importance of chaos narratives being heard, he also indicates that it will be beneficial for them ultimately to be transcended [8, p.110]. Restitution narratives are encouraged by biomedical approaches and often by well-meaning clinicians, but according to Frank, a more authentic understanding of the meaning of illness is found through quest narratives [8, Ch.6]. Quest narratives interpret illness experiences as a journey from which something might be gained, and may help allow an ill person to fully own their experience in virtue of their activities of narration. An example is John Donne's recasting of his critical illness as a spiritual journey [8, p.116]. Frank's view implies narrower criteria for what will count as a narrative - since a description of chaos is on this view a loss of narrativity - and makes normative claims about what narratives are most beneficial.

Narrow conceptions of narrative are potentially problematic in several respects. They potentially constrict rather than aid self-understanding and the struggle for meaning in illness, if they encourage some ways of interpreting experience over others [12;23]. They risk suppressing alternative kinds of self-understanding - and experiences of formlessness, meaninglessness, and silence - and may encourage self-deception [10]. They seem to imply that patients whose experiences do not exhibit the 'quest' form have somehow failed.

Even conceptions of narrative (or 'beneficial narrative') that are broader than Frank's are liable to the criticism of being too narrow. Conventions about narrative, or narrative form itself might constrain how patients and clinicians are permitted or encouraged to understand illness experiences, and prevent acknowledging experiences of chaos or meaninglessness [12;23]. Some patients indicate that non-narrative forms of selfunderstanding are useful for them, for example those achieved through poetry or dance [24].

The critique that narrative may be too narrow a concept through which to understand illness experience has a parallel in relation to the 'medical narrative'. Regarding the 
clinician's interpretation of a patient's situation as a narrative might also be constraining. If clinicians focus too much on finding the story that makes sense of the situation, they might risk getting 'locked in' to a particular narrative too early in the diagnostic process, focussing on confirming the expected diagnosis and ignoring or dismissing inconsistent details [15, p.17-19;17, p.8].

Narrative approaches also face practical issues. One is the time constraints experienced by most clinicians $[1 ; 2 ; 25]$. David Morris reports a typical reaction from clinicians to his discussions about narrative approaches: "'What you say about narrative is very interesting,' I hear repeatedly. 'Thanks so much for coming. But I have seven minutes per patient.' End of story" [1, p.88]. Second, not all patients want to spend additional time or engage deeply with their clinician, and not every patient will need or want empathic understanding of their story in order to achieve their healthcare goals [1;13, p.84]. Third, while narrative approaches need to take patient statements seriously, there are cases where clinicians may be rightly wary of taking patient reports at face value. For example, patients' claims about being happy to risk their health rather than alter their lifestyle might be rationalisations that obscure significant fears, while the veracity of reports about behaviours (including medication use) might be influenced by embarrassment or a desire to please the clinician $[26$, p.1463-4].

To evaluate these various critical concerns about narrative, we next examine narrative epistemologically. Any method of gathering knowledge, after all, will have strengths and weaknesses, and an epistemological understanding can help to identify the circumstances under which it is likely to be reliable, and when we might want to be cautious about its use. This is true no less of narratives than of randomised controlled trials. For instance, with randomised trials, we recognise that they can have strong internal but weak external validity, and where we judge that this is so, are cautious in applying their results to other populations. An epistemological account of narrative should similarly offer guidance on its strengths and weaknesses, and when we should apply caution. 


\section{Narratives and their contributions to knowledge}

Narratives describe events that are somehow connected and occur at different times. ${ }^{5}$ These basic features are evident in the conceptions of narrative invoked by scholars on narrative approaches in healthcare. Assuming these basic features, we examine two ways of understanding how narratives could provide knowledge: (1) that they provide causal knowledge, and (2) that they provide knowledge about human actions and agency. We then argue for a pluralist view on which narratives are understood to convey knowledge of causes and/or knowledge of human action; and more generally, that they can add epistemic value by providing reasons to interpret events using particular descriptions and/or by informing judgements about the validity of different ways of interpreting events.

\section{Causal knowledge}

The idea that events in narratives are causally connected goes back to Aristotle [27, p.2], and suggests that the kind of knowledge we acquire from narratives may be causal. In the twentieth century, positivists claimed that knowledge from narratives must be causal [28]. This claim however, runs into the problem that many narratives include connections between events that are seemingly not causal. A classic example is a short narrative from Aristotle: "the statue of Mitys at Argos killed the author of Mitys' death by falling down on him when a looker-on at a public spectacle" [in 27, p.5]. In this example, the death of the murderer is not causally related to his murdering Mitys, yet most accept that this is a narrative connection. Another kind of example involves 'teleological' connections, where one event is understood in relation to another that is its goal; for instance, the connections between obtaining Flint's treasure (the goal) and the events that lead up to it in Treasure Island. This kind of connection cannot be understood as solely causal: although some of the events in Treasure Island causally contribute to finding the treasure, other events are obstacles to this goal [27, pp.8-10]. They are understood in relation to the goal but as obstacles, not causes.

Those who regard narratives as sources of causal knowledge typically argue that such noncausal connections tend to be misleading. Currie argues that non-causal connections such as

5 We follow the usual practice of using 'events' in a general way which includes psychological 'events' such as making a decision, having a reason for action or forming an intention. 
that in the Mitys story work by generating the illusion of a causal relation, into which the audience willingly enters, in recognition of apparent poetic justice in Mitys' statue killing his murderer [29]. Velleman argues that narratives seem to us to explain events because they evoke familiar emotional sequences and so can make us think we understand some sequences of events when we do not [27]. Anxieties over the unscientific nature of narratives, connected to these non-causal connections, lead to claims that narratives are necessarily misleading or distort the truth. Since narratives are essentially interpretive they depend on selection of which events to include, and present them in certain ways narration involves imposing form onto events which in themselves have no such structure $[30$, p.5]. White, for example, takes the exclusion of some facts and the selection of others to be necessarily distorting, giving events certain meanings that they do not inherently possess [31].

However, there are two main reasons to be dissatisfied with the view that the knowledge generated by narrative is exclusively or primarily causal. First, while narratives often include information about causal connections between events, they also often include other kinds of connections, that may nonetheless be knowledge conveying (as we discuss below). The causal view is too narrow as it excludes this possibility. Second, the view that narrative explanations reduce to causal explanations with some additional, potentially misleading elements simply writes narrative off as an epistemic tool, rather than helping us distinguish when it might be useful, and when it is likely to mislead.

\section{Knowledge about human action}

Other views of narrative and knowledge seek to explain what of epistemic value, other than causal knowledge, might be provided by narratives. Such views begin by distinguishing between causal explanations and explanations in terms of reasons for action, and regard narrative explanations to fall into the latter category [32;33;34]. Although a reason for action could be considered an event that causes an action as a second event, explanations in terms of reasons differ from causal explanations because they allow us to understand the agent's decisions first-personally [32, p.128]. A reason for action will make sense only as part of a web of reasons, beliefs, and attitudes, in the context of which an agent decides, so explaining action involves unpacking this web to some extent [34, p.14-15]. Narratives thus 
have a distinctive role in understanding the meaning of events from particular perspectives [35, p.191]. ${ }^{6}$ Some make a further claim that narrative is an apt form in which to provide reasons-based explanations because there are similarities between narrative structure and the structures of action and practical reasoning [36;33]. This view of what sort of knowledge narratives can provide seems consistent with many of the claims of narrative approaches in healthcare, explaining why narrative may be an apt form in which to examine illness experiences and their impact on self-understanding. ${ }^{7}$

The view that narrative contributes to understandings of reasons for human action captures important points regarding the potential epistemic value of narrative: it suggests narratives enable articulation of the meaning of events from particular perspectives and provide insight into the meaning-making interpretive activities of individuals. But there are reasons to avoid understanding the epistemic value of narrative entirely in terms of reasons-based explanations. First, it seems clear that narratives can communicate not only connections of reasons and actions, but also other connections - including causal $[32, p, 140 ; 38]$ and teleological connections. A purely reasons-based view of narrative's epistemic contribution is overly narrow just as the purely causal view is. Second, while the reason-based view is intended to show that narratives can provide true knowledge, it does so by confirming a strong distinction between 'causal/scientific knowledge' and 'narrative knowledge'. Ricoeur, for example, argues that narratives provide a different sort of knowledge to science, involve different senses of truth and certainty, and require different kinds of truth-test [36, p.22]. Such a strong distinction makes it difficult to reconcile the two kinds of knowledge, implying that 'narrative knowledge' cannot be assessed in the same ways as scientific knowledge. This view thus also fails to offer guidance on when knowledge from narratives is likely to be reliable, and when misleading - a deficit that is particularly important in healthcare contexts.

6 This aligns with a large body of work which regards the human and the physical sciences to involve quite different forms of knowledge, sometimes distinguished as explanation (eklären) and understanding (verstehen) [33, p.24-5].

$7 \mathrm{It}$ also connects to reasons many have suggested drawing on narrative to think about personal identity [36] and/or self-conceptions that promote flourishing, particularly in the context of experiences such as illness [20;37]. 


\section{Plural forms of contribution to knowledge}

As we have seen, there are various ways events in narratives can be connected. As well as causal and reasons-for-action connections, there are teleological connections, and connections of 'poetic justice'. ${ }^{8}$ This suggests that the epistemic value of narrative does not lie solely in providing knowledge about any particular sort of connection between events [41]. We therefore propose a pluralist view which recognises that narratives can involve multiple kinds of connections between events, and can provide diverse kinds of knowledge about the events they describe. They can provide epistemic value of various sorts and in different ways. As we now explain, the central feature of what makes connections narrative connections is that the description of each event in the narrative is influenced by the other events that are included.

We can begin by recognising that events can be accurately described in numerous ways. Descriptions may be from different perspectives, or focus on different aspects of events. New true descriptions of an event can also arise in light of events occurring later. Danto calls sentences that describe events in ways that can be considered true in virtue of later events 'narrative sentences'. An example is "Aristarchus anticipated in 290 BC the theory which Copernicus published in AD 1543". In this example, Aristarchus' theory can be accurately described as an 'anticipation' from AD 1543 onwards, although this would not have been a true description before AD 1543 [42, pp.149-59]. Narrative sentences connect events by describing those events in ways that are true in virtue of other, temporally distinct, events.

While this means there is a potentially infinite number of true descriptions of any event, where an event is included in a narrative, some of its potential descriptions will be inappropriate because they would not make the sequence of events intelligible [43]. Koppe provides an example of a simple narrative:

(1) The other day, my neighbor called to ask if he could borrow my car.

(2) I gave him the keys.

(3) The next day, he used my car to rob a bank. [43, p.104]

8 Various other kinds of connection are discussed in the philosophy of literature and narratology; see e.g. $[39 ; 40]$. 
Now assume that event (1) is also truly described by "The other day, my neighbor talked to me on the phone" or "On May 15, a man asked me a question" [43, p.105]. If (1) were replaced with these descriptions, the intelligibility of the narrative would be reduced, perhaps entirely removed. The acceptable ways to describe (1) are circumscribed by its inclusion in this narrative.

Generalising from Danto's and Koppe's points, we understand narrative to involve the description of events in ways influenced by the other events in the narrative. ${ }^{9}$ That the events mutually influence each others' descriptions enables us to understand why, and the sense in which, the interpretive judgements involved in the given descriptions are apt. This implies that a narrative can, in presenting us with a sequence of events, provide us with reasons to interpret the events in particular ways, suggested by the descriptions provided. By connecting Aristarchus' theory to Copernicus', we are given reasons to consider the former an anticipation, and the latter a rediscovery. Or, similarly, a narrative might provide reasons to regard an event as the cause of, an intentional action towards achieving, a hindrance to, or an expression of poetic justice in relation to, some other event. Events might even be 'connected' or juxtaposed in ways that we could think of as negative, so that an event is seemingly inconsistent with, or raises questions about, or is ironic in light of, some other event.

Telling a narrative can, then, be a form of reason-giving to others, insofar as the descriptions offered of each event demonstrate the validity or fruitfulness of the descriptions of other events. This implies that narratives can provide us with new knowledge: they can demonstrate why events can be regarded as falling under particular descriptions, or the validity of the interpretive judgements involved in those descriptions. The epistemic value of a narrative could also thus include not only the information its descriptions provide, but implied directions for further attention or investigation in relation to the judgements involved in those descriptions.

9 Mink [41, pp.550-6] makes a similar proposal, and see $[27$, p.8]. 
This pluralist conception of the kinds of knowledge offered in narratives avoids the two problems to which the causal and reasons-based views were liable. First, it avoids the narrowness charge by accepting multiple sorts of connections. Second, it avoids distinguishing between 'narrative knowledge' and other kinds of knowledge, instead recognising that narratives can provide knowledge about multiple sorts of connections between events, and offers other epistemic goods (such as guidance on directions for further investigation, or an invitation to consider the validity of certain interpretive judgements). Since on this view narratives provide knowledge of the same sort as that obtained in other ways, this knowledge can be assessed in familiar ways: both the descriptions of particular events, and the connections between events, can be assessed for truth against the world, just as we assess non-narrative descriptions against the world. Further, the account suggests some of the ways that knowledge from narratives can tend to go awry, and hence some areas for caution. As we discuss below, this feature is particularly useful for narrative approaches in healthcare.

\section{Resolving theoretical criticisms of the use of narrative in healthcare}

In this section we first explain how the pluralist conception of narrative avoids being too narrow, in relation to both the patient's and the medical narrative. We then show it avoids the charge of being so broad as to be trivial by drawing out five ways in which, implicitly, clinical attention to narratives can be useful in improving patient care.

In relation to the narrowness charge, the pluralist conception of narrative clarifies that where narrative approaches are used to help develop or convey understanding of illness experiences, they need not impose particular understandings of illness onto patients or constrict what are regarded as valid or beneficial forms of self-understanding. Since a narrative can on this view include multiple kinds of connections between events, it can include chaotic or inconsistent elements - for example, by describing them as inconsistent, difficult to understand, or apparently meaningless. Although there might be similarities between some patients' illness experiences, and commonly found patterns such as 'recovery narratives' or 'transformation stories', the pluralist conception reminds us that a main reason for using narrative to examine illness experience is to avoid homogenising patients' experiences [8]. Narration may find patterns and integrate information, but part of 
the epistemic strength of narratives is that they can also contain inconsistences and incoherence [36, pp.141-3;161]. Attention to narrative in our pluralist sense would thus encourage recognition of chaotic experience rather than omitting it. ${ }^{10}$

Similar points apply to the corresponding criticism that a narrative approach narrows possibilities in clinicians' thinking. On the pluralist conception of narrative, elements that do not easily fit into the whole can be included. In medical narratives, this might involve connections between events like 'symptom A is puzzling in light of test result B' or 'test result $A$ and symptom $P$ fit with diagnosis $X$. Yet test result $B$ is unexpected in light of diagnosis $X^{\prime}$. If the process of constructing a medical narrative is understood on the pluralist conception, then, this should actually encourage attentiveness to details that seem not to easily fit.

The same point also gives us the first reason to think that, although the pluralist conception of narrative is intentionally inclusive and thus quite broad, it is not so broad as to be trivial. Narrative differs from other ways of understanding different events together - such as classifying them as instances of a category, or seeing them as parts of a recognisable pattern - which involve finding similarities or consistencies between them [41]. Narratives can pinpoint similarities and consistencies, but also dissimilarities and inconsistencies (Ricoeur's "synthesis of the heterogeneous" [36, p.141]). For this reason, regarding the clinical process of understanding a patient's healthcare concerns as a narrative has advantages over regarding it as a process of fitting the concerns into some category, or finding the pattern it most resembles. Such approaches would, indeed, tend to encourage omitting whatever details are difficult to accommodate in the category or the pattern. Thinking of the process as constructing a narrative on our pluralist conception, in contrast, encourages less distortion. Thus while the view avoids the narrowness charge, it avoids the charge of being so broad as to be trivial by showing what is gained in thinking of clinical procedures in narrative terms.

10 This does not answer the criticism that some may prefer to pursue self-understanding in nonnarrative forms such as poetry or dance. Rather than expanding the notion of narrative to include these (which do not meet even the minimal understanding of narrative noted at the start of section 3), we recognise that some may prefer non-narrative forms of self-understanding [contra, e.g., 11]. 
A second advantage of the pluralist conception of narrative is that it confirms that narratives can represent events from particular perspectives and are thus a suitable form in which to explore the meaning of events to patients (though it holds that this is not their only use). This is what underpins claims relating to narrative being a suitable form for patients to develop self-understanding, and to communicate this to clinicians. Understanding of how things seem from the patient's perspective might be undertaken in non-narrative forms, but narrative will be a relatively easy and efficient method for this purpose. Further, thinking of patients' presentations as part of their individual narratives encourages clinicians to think about how the experiences seem to patients, and how the illness events connect to other events in their life, and their beliefs and attitudes.

How a clinician listens to a patient can make the difference between providing care that is, and is not person-centred. Attending to patient narratives can help clinicians to acknowledge and respect patients' experiences, in ways that communicate empathy, improve therapeutic relationships and avoid reducing experiences of illness and healthcare to their biomedical aspects.

Third, the pluralist conception allows that patients' narratives can be a source of causal knowledge - including of what may have contributed to their condition (e.g., lifestyle or lifestyle changes, recent exposure to specific infections, etc.), as well as knowledge about the events that caused the patient to seek advice (e.g., patients' experiences of concern), which can be relevant to meeting the patient's needs effectively. Consider the following example:

Amita presents to her GP, concerned about a minor skin rash on the hands. The GP, whose appointments are running 45 minutes late, quickly moves to diagnostic mode, questioning her about how the rash began, its duration, associated itches or pain, recent exposures to allergens, and so on. Amita answers each of these questions in turn: the rash came on over several days following a visit to another state; yes, it is slightly uncomfortable; yes, she feels otherwise well; no, she is not aware of any allergies but may have been exposed to unfamiliar flora or soap products on her trip. The GP begins examining the rash while 
explaining a range of potential causes, ready to reassure Amita that there is unlikely to be reason to worry and that she should monitor the rash and return if it does not clear up on its own within two weeks. At this point Amita interjects to explain her main reason for seeking a consultation is that just before the rash began, she spent time with an infant relative with leukaemia who was at the time neutropenic. She has reported the rash to her relatives who discussed the matter with the children's hospital, and been asked to have the spots checked for varicella so that preventative steps can be taken if the child has been exposed. The GP takes swabs for testing and assures the patient she will call with results as soon as possible.

The point we want to make with this example is that the specific concern of this patient is easily accessible by listening to a brief narrative, while even the most thorough clinician would be unlikely to uncover this specific goal of the healthcare encounter by questions focusing on pathophysiological features of the rash (although a general question like "Have you any particular questions you'd like to ask me about the rash?" might elicit the relevant narrative). While clinicians' knowledge and experience provide them with ways to anticipate the kinds of questions they need to ask in many cases, there will always be some limitation on the effectiveness and efficiency of that method, because clinicians cannot always know what it is they need to know. A patient's narrative will pick out the events they take to be relevant, to their condition or their reasons for seeking advice. Even if the patient offers other events in query, or those events are subsequently accepted to be causally unrelated, it might still be useful to the clinician and patient to raise and discuss events the patient thinks could be connected to their condition, for example to ensure fears are addressed, or to facilitate effective treatment.

Fourth, the pluralist conception of narrative provides a way of understanding the sense in which communication can be facilitated between patient and clinician by using narratives. On this view, in connecting events together in certain ways, narratives present reasons to interpret some event in a certain way, and invite consideration of the validity of the judgments involved in the offered descriptions, including consideration of how events may be interpreted from different perspectives. As the clinician listens to the patient's narrative and the patient to the medical narrative, reasons to regard the events therein under the different descriptions are being exchanged. A patient may offer, for instance, an event that 
occurred prior to the onset of their complaint as potentially relevant to the eventual description of it; or details of their social circumstances as reasons to respond to the experiences in particular ways. A clinician may offer a blood glucose test result, combined with their knowledge of normal or desirable ranges, as reasons to understand certain patient experiences under the description of 'symptoms of pre-diabetes'. On our approach, this can be regarded as an exchange of reasons and negotiation of descriptions of the events of illness, where more than one narrative description is possible. Regarding the exchange in this way may enable patients to re-interpret their experiences in ways that point to diagnosis and therapeutic responses, while regarding the process as one of respectful, rational and enabling exchange rather than as a matter of the clinician dismissing or seeing the patients' perspective as defective or deficient and needing to be replaced or corrected.

Finally, the pluralist conception provides guidance on areas for caution in using narratives. Some particular areas for caution relate to ways that narrative might mis-describe events. For instance, misleading descriptions can occur when an interpretation of events mistakes one kind of connection between events for another, such as interpreting a temporal connection as a causal one. For example, some vaccine-hesitant parents explain their stance by telling a story about a child becoming ill immediately following a vaccination. In some of these cases they may have witnessed a vaccine reaction; in others, while the illness may be causally unrelated, the parents' interpretation of the sequence of events as causal could lead them to avoid later vaccinations. The narrative told by the parents can be identified as potentially misinterpreting the events. Another area for caution is the possibility that a clinician too quickly finds some connection that appears to be explanatory, and ceases to search for others. Something like this seems to occur when symptoms of physical illness are ignored in people with mental illnesses, as the physical symptoms are taken to originate in their mental illness. Again, this results in a medical narrative that contains an incorrect interpretation of the symptom as a symptom of mental illness, which can be interrogated. Since our pluralist conception also implies that knowledge gained from narratives is continuous with other knowledge, potentially misleading narratives can be either assessed empirically and critically. On the pluralist conception 'listening to narratives' is not some silver bullet for achieving a correct understanding, but rather encourages critical thinking 
about how both clinician and patient are interpreting events and assessment of interpretations in light of other knowledge. This supports exchange of narrative interpretations in the respectful and enabling ways associated with $\mathrm{PCH}$.

\section{Responding to practical problems}

In this section we argue that the pluralist conception of narrative provides some guidance regarding practical barriers relating to time constraints, patient expectations, and limitations on accepting patient narratives at face value.

In relation to time constraints (which are of course, a reflection of economic constraints), our conception allows that listening to a patient's narrative does not require a clinician to listen to an entire life story: the relevant story may be quite short and relatively superficial. This is consistent with empirical evidence showing that although clinicians may be wary of inviting a patient narrative for fear that this will involve indefinite listening and wading through many irrelevant details, this is unlikely. Langewitz et al's classic study examined how long patients spontaneously speak for at the start of a consultation if uninterrupted. The mean talking time was 92 seconds; $78 \%$ of patients finished in under two minutes, and only around $2 \%$ spoke for more than five minutes [44]. Other studies report similar results $[45,46]$. Overall consultation times range between 7.6 to 17.6 minutes in European countries and the USA [47], so listening to this spontaneous narrative seems unlikely to take up 'too much' of the clinical consultation in most cases.

Nor does it seem that patients often divert onto long, irrelevant tangents. Langewitz et al report that "[i]n all cases doctors felt that the patients were giving important information and should not be interrupted." This suggests (but does not confirm) that allowing patients to direct the initial part of the consultation may be as or even more time-efficient than gathering the information by clinician-directed questioning. ${ }^{11}$ This is consistent with reports from clinicians that practicing narratively or in a patient-centred way can actually save time overall $[2$, p.668;14, p.67;18, p.1899]. On our view, a narrative approach does not mean that

11 Two classic studies of how much time patients were given to speak before being interrupted by the clinician found averages of 18 and 23.1 seconds [47]; a recent study reported 9.5 seconds [48]. 
clinicians must spend a great amount of time listening to patients; it is more important how the clinician listens, interprets, and responds to the narrative or narrative fragments the patient offers as relevant.

Similarly, listening to a patient's story does not always require deep empathic engagement. Listening to what a patient offers as a narrative and considering how it relates to and might be responded to in the light of a medical narrative can be simply a useful method of collecting relevant information from the patient. Attention to narratives can also, however, encourage respectful and responsive attitudes in clinicians, and develop listening skills that can help in recognising when deeper engagement, and further exploration of the patient's perspective, may be warranted [13, p.84;49]. This can occur, first, through regarding the information the patient provides as a narrative they are telling, with the implications this has for recognising their subjective perspective. A narrative may reveal specific things the patient seeks from a consultation, such as desires for understanding or recognition of suffering. Second, a change of attitude can occur through recognition that the medical narrative is also an interpretation, with the accompanying awareness of how it may impact on the patient's understanding of their experience.

The third issue relates to the fact that there are sometimes reasons for clinicians not to take a patient's narrative at face value. If patients are deceiving clinicians or themselves, perhaps out of embarrassment or fear, not challenging their narrative (i.e. by suggesting alternative interpretations or configurations within it) may be remiss. It is important to recognise that on our account, attending to a narrative does not mean accepting it uncritically: we may need to be critical or sceptical of narratives, just as with other forms of evidence. Where concerns that a patient's narrative is false or self-deceptive are based on good listening practices, on respectfully questioning but not dismissing what patients say, challenging and offering alternative interpretations in response to a patient's narrative could be appropriate. This kind of case is likely to be difficult in practice [26], and clinicians will need to take into account the ongoing relationship and a range of other considerations, but our account suggests that engaging with these patients by suggesting a reinterpretation of their narrative could be both respectful and beneficial to the patient. 


\section{Conclusion}

We have made the case for understanding narratives as accounts of events in which the way each event is described is influenced by the ways other events in the narrative are described. This view of narratives enables recognition that they can contribute knowledge of several different kinds of connections between events, and add further epistemic value by suggesting potentially useful lines of inquiry. When combined with the view that narrative approaches to healthcare involve considering both patients' informational offerings and professional understandings as narratives, our account is able to overcome the major theoretical and practical criticisms that have been levelled against the use of narrative approaches in healthcare. In doing so, it helps explain how clinical attention to patient narratives could be of use in healthcare, and why and how narrative approaches are consistent with person-centred healthcare, potentially helping to achieve features of $\mathrm{PCH}$ such as treating patients as persons worthy of respect and compassion; recognising and responding to patients' subjective experience of illness and care; and developing therapeutic relationships that support (or at least do not undermine) patients' abilities to participate actively in their healthcare and ensuring their own values influence decisionmaking. More generally, we hope to have shown that narrative approaches in $\mathrm{PCH}$ can benefit from paying attention to the epistemological as well as the ethical possibilities of clinical attention to narratives.

\section{Acknowledgements}

The first author was supported by the Australian Research Council (CE140100012). The third author was part supported by the Wellcome Trust (209811). Our thanks to participants at the European Society for Philosophy of Medicine and Health Care $32^{\text {nd }}$ annual conference for comments and questions on an earlier version of some of the paper.

\section{References}

1. Morris, D.B. (2008). Narrative medicines: challenge and resistance. Permanente Journal 12(1), 88-96

2. Moore, L., Britten, N., Lydahl, D., Naldemirci, O., Elam, M. \& Wolf, A. (2017). Barriers and facilitators to the implementation of person-centred care in different healthcare contexts. Scandinavian Journal of Caring Sciences 31, 662-673. 
3. Savard, J. (2013). Personalised medicine: A critique on the future of health care. Journal of Bioethical Inquiry 10, 197-203.

4. Vogt, H., Hofmann, B., Getz, L. (2016). Personalized medicine: Evidence of normativity in its quantitative definition of health. Theoretical Medicine and Bioethics 37(5), 401-416.

5. Hogarth, S. \& Marks, L. (1998). The golden narrative in British medicine. In: Narrative based Medicine: Dialogue and Discourse in Clinical Practice (ed. T. Greenhalgh \& B. Hurwitz), pp. 140-148. London: BMJ Books.

6. Entwistle, V.A. \& Watt, I.S. (2013). Treating patients as persons: A capabilities approach to support delivery of person-centred care. American Journal of Bioethics 13(8), 29-39.

7. Buetow, S. (2016). Person-centred health care: Balancing the welfare of patients and clinicians. London: Routledge.

8. Frank, A. (1995). The Wounded Storyteller: Body, Illness, and Ethics. Chicago: University of Chicago Press.

9. Woods, A. (2010). The limits of narrative: provocations for the medical humanities. Medical Humanities 37, 73-78.

10. Woods, A. (2012). Beyond the Wounded Storyteller: rethinking narrativity, illness and embodied self-experience. In: Health, Illness and Disease: Philosophical Essays (ed. H. Carel \& R. Cooper), pp. 113-128. Newcastle: Acumen.

11. McKechnie, C.C. (2014). Anxieties of communication: the limits of narrative in the medical humanities. BMJ Medical Humanities 40, 119-24.

12. Conway, K. (2013). Beyond words: Illness and the limits of expression. Albuquerque: University of New Mexico Press.

13. Kalitzkuz, V. \& Matthiessen, P.F. (2009). Narrative-based medicine: Potential, pitfalls, and practice. Permanente Journal 13(1), 80-86.

14. Charon, R. 2006. Narrative medicine: Honoring the stories of illness. Oxford: Oxford University Press.

15. Montgomery Hunter, K. (1991). Doctor's stories: The narrative structure of medical knowledge. New Jersey: Princeton University Press.

16. Montgomery Hunter, K. (1996). Narrative, literature, and the clinical exercise of practical reason. Journal of Medicine and Philosophy 21, 303-320. 
17. Greenhalgh, T. \& Hurwitz, B. (1998). Why study narrative? In: Narrative based medicine: Dialogue and Discourse in Clinical Practice (ed. T. Greenhalgh \& B. Hurwitz), pp. 3-16. London: BMJ Books.

18. Charon, R. (2001). Narrative medicine: A model for empathy, reflection, profession, and trust. Journal of the American Medical Association 286(15), 1897-1902.

19. Kleinman, A. (1988). The Illness Narratives: Suffering, Healing, and the Human Condition. New York: Basic Books.

20. Nelson, H.L. (2001). Damaged Identities, Narrative Repair. New York: Cornell University Press.

21. McNaughton, J. (1998). Anecdote in clinical practice. In: Narrative based medicine:

Dialogue and Discourse in Clinical Practice (ed. T. Greenhalgh \& B. Hurwitz), pp. 202-211. London: BMJ Books.

22. Montgomery Hunter, K. (1997). Aphorisms, maxims, and old saws: narrative rationality and the negotiation of clinical choice. In: Stories and Their Limits (ed. H.L. Nelson), pp. 215-231. New York: Routledge.

23. Garden, R. (2010). Telling stories about illness and disability: The limits and lessons of narrative. Perspectives in Biology and Medicine 52(1), 121-135.

24. Woody, J.M. (2004). When narrative fails. Philosophy, Psychology and Psychiatry 10(4), 329-45.

25. Buckley, C., McCormack, B. \& Ryan, A. (2017). Working in a storied way - Narrativebased approaches to person-centred care and practice development in older adult residential care settings. Journal of Clinical Nursing 27, e858-72.

26. Entwistle, V.A., Cribb, A., Watt, I.S., Skea, Z.C., Owens, J., Morgan, H.M. \& Christmas, S. (2018). "The more you know, more you realising it is really challenging to do": Tensions and uncertainties in person-centred support for people with long-term conditions. Patient Education and Counselling 101, 1460-7.

27. Velleman, J.D. (2003). Narrative Explanation. Philosophical Review 112(1), 1-25.

28. Hempel, C.G. (1942). The function of general laws in history. The Journal of Philosophy 39(2), 35-48.

29. Currie, G. (2006). Narrative representation of causes. Journal of Aesthetics and Art Criticism 64(3), 309-316. 
30. White, H.V. (1987). The Content of the Form: Narrative Discourse and Historical Representation. Baltimore: Johns Hopkins University Press.

31. White, H.V. (1975). Historicism, history, and the figurative imagination. History and Theory 14(4), 48-67.

32. Dray, W. (1957). Laws and Explanation in History. Oxford: Clarendon.

33. Carr, D. (2008). Narrative explanation and its malcontents. History and Theory 47, 19-30.

34. Bevir, M. (2000). Narrative as a form of explanation. Disputatio 9, 10-18.

35. Ricoeur, P. (1992). Narrative Identity. In: On Paul Ricoeur: Narrative and interpretation (ed. D. Wood), pp. 188-199. London: Routledge.

36. Ricoeur, P. (1992). Oneself as Another. Trans. K. Blamey. Chicago: University of Chicago Press.

37. Mackenzie, C. \& Poltera, J. (2009). Narrative integration, fragmented selves, and autonomy. Hypatia 25(1), 31-54.

38. Steuber, K.R. (2012). Understanding versus explanation? How to think about the distinction between the human and the natural sciences. Inquiry 55(1), 17-32.

39. Lamarque, P. (2009). The Philosophy of Literature. Oxford: Blackwell.

40. Klauk, T. (2016). Is there such a thing as narrative explanation? Journal of Literary Theory 10(1), 110-138.

41. Mink, L.O. 1970. History and fiction as modes of comprehension. New Literary History $1(3), 541-558$.

42. Danto, A. (1985). Narration and Knowledge. New York: Columbia University Press.

43. Koppe, T. (2016). Narrative events. StoryWorlds 6(1), 101-116.

44. Langewitz, W., Denz, M., Keller, A., Kiss, A., Ruttimann, S. \& Wossmer, B. (2002). Spontaneous talking time at start of consultation in outpatient clinic: Cohort study. BMJ $325,682-3$.

45. Blau, J.N. (1989). Time to let the patient speak. BMJ 298(6665), 39.

46. Labaf, A., Masoomi, R. \& Raeisi, M. (2015). How long it takes patients initial statement of concerns? Brief report. Tehran University Medical Journal 73(8), 608-13.

47. Lussier, M.T. \& Richard, C. (2006). Time to talk. Canadian Family Physician 52, 1401-2.

48. Movaffaghi, Z., Makarem, A., Beyraghi, N., Hosseini, F. \& Farsi, M. (2013). Time allowed to patients to explain their problem in outpatient clinics of Mashhad University of Medical Science hospitals. Iranian Journal of Medical Education 13(7), 570. 
49. Rehmann-Sutter, C., Porz, R., \& J. L. Scully. (2012). How to relate the empirical to the normative: Toward a phenomenologically informed hermeneutic approach to bioethics. Cambridge Quarterly of Healthcare Ethics 21(4), 436-47. 